\title{
Basic Selection and Analysis of Harbin Ice and Snow World Theater Project
}

\author{
Xiaomeng Zhang ${ }^{1}$, Wenting Liu ${ }^{1}$, Yilun Zhou ${ }^{1}$, Ziao Liu ${ }^{1}$, \\ ${ }^{1}$ China Architecture Design \& Research Group, Beijing 100044, China
}

\begin{abstract}
Harbin Ice and Snow World Project totals 98,000 square meters, consisting of Iceberg Pavilion, Dream Ice and Snow Pavilion, Ice and Snow Show, and Ice and Snow Art Museum.This project mainly introduces the foundation selection and structural design of the Harbin Ice and Snow World Show, verifies the feasibility of the project implementation, and analyzes the rationality of the structural foundation layout through structural design and structural calculation analysis.
\end{abstract}

\section{Project Overview}

The construction site of the project is located in the West$\mathrm{B}$ area of the Sun Island Scenic Spot in Harbin City. The east side of the project land is Snow North Road, and it is adjacent to Songbei Road by the north-south urban green belt. The south, west and north sides are surrounded by Bingfeng Road.On the south side of Bingfeng Road is the current Harbin Sun Island Garden Hotel, on the west side is a large wetland park, and on the north side is near Songhua River.
The total land area of the project is about 87 hectares, and the total construction area is 96,000 square meters. The main functions are composed of outdoor parks and indoor venues. The outdoor park is composed of ice construction and ice sculpture exhibition area, ice slide area, ice rink recreation area, non-powered recreation area, ferris wheel and other functions.Indoor venues include: Iceberg Pavilion, Dream Ice and Snow Pavilion, Ice and Snow Show, Ice and Snow Art Museum, Comprehensive Museum, Ticket Office at the main and secondary entrances as well as related supporting facilities.This paper analyzes the basic form and layout of the ice and snow show.

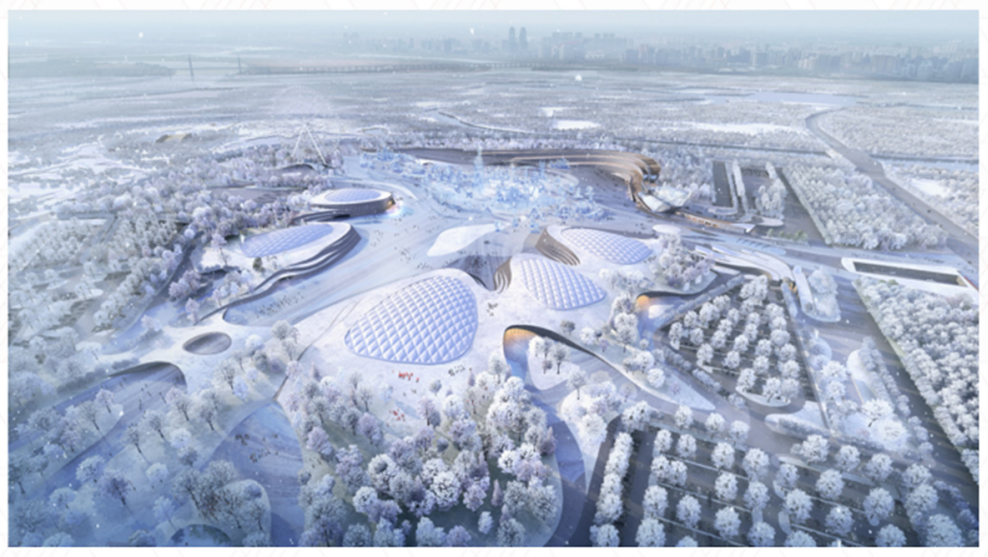

Figure 1. Architectural renderings.

he design service life of this project is 50 years. The safety grade of the building structure is Grade I, the fire protection grade of the building structure is Grade I, and the design grade of the foundation foundation is Grade A.According to the Code for Seismic Design of Buildings (GB50011-2010) (2016 Edition) ${ }^{[1]}$, the Seismic Group I in the area where the project is located, the site category is Class III, and the seismic grade is 7 degrees $0.1 \mathrm{~g}$, which is the key fortification class (Class B).The structural system is a frame shear wall structural system.

\section{Site engineering geological conditions}

The project was conducted geological exploration by China Railway Modern Survey and Design Institute Co., Ltd., and provided the Geotechnical Engineering Investigation Report of Harbin Snow and Ice World Four- 
Season Snow and Ice Project (Detailed Survey) (Project No. : ZT-2020-030) compiled in April $2020^{\text {[2]. }}$.

The survey results show that the proposed site has a single landform type, no Holocene active faults, no adverse geological processes and geological disasters, and the site and foundation are stable, so it is suitable for the construction of the project.

According to the lithologic structure and engineering geological characteristics of the rock and soil layer, the stratum of the proposed site can be divided into unit layers from top to bottom: (1) mixed soil, (2) silty clay, (2) silty soil, (3) fine sand, (4) fine sand, (5) medium sand, (5) silty clay, (6) coarse sand, (6) silty clay, (7) fully weathered mudstone.

The special soil is (1) miscellaneous filling soil, (2) silty soil and (3) fine silty sand.Miscellaneous fill is mainly composed of clayey soil, brick, gravel and living construction waste, which is accumulated recently. The thickness of the layer is $1.10-15.80 \mathrm{~m}$, and this layer is widely distributed, so it is not suitable to be used as the foundation bearing layer.The silty soil layer is in the form of soft plastic and fluid plastic, with high compressibility, rich in organic matter and local humus. The thickness of the layer is $0.60-7.50 \mathrm{~m}$, and this layer is missing locally, so it is not suitable to be used as the foundation bearing layer.According to the comprehensive discrimination, (3) fine silty sand layer is slightly to medium liquefaction, while other soil layers are not liquefied.Due to the large upper load, the shallow foundation scheme can not meet the bearing capacity requirements, so the pile foundation scheme is recommended.

\section{Analysis of pile foundation type selection}

\subsection{Compressive pile design}

Different pile lengths and pile foundation technology are compared [3] [4], as shown in Fig. 2, and the performance of different piles is analyzed:

1. With the same diameter and the same pile length, the grouting bearing capacity after the bored cast-in-place pile is the highest, followed by the pipe pile and the bored cast-in-place pile.

2. If the prefabricated pile is adopted, the length of the pile is generally 15 meters, and the longer pile needs to be connected with the pile. Moreover, when the construction period is tight, the purchase time of pipe pile needs to be estimated in advance, and the pipe pile is easily restricted by the requirements of the lower soil layer, which affects the piling effect.Specific by the local construction conditions and project costs to determine.

3. Restriction conditions of pipe pile construction:

(1) Static pressure construction method: Piling in fine sand and medium sand layer is easy to cause problems.

(2). Hammer construction method: the noise is larger, and the impact on the surrounding environment is greater.

(3) Extracted pile: the head of the extension pile is not firm, so it can only play the bearing capacity of the upper pipe pile.

(4)Restriction condition of bottom expanding pile: in the construction process of bottom expanding pile, it is easy to appear sediment, which will affect the bearing capacity of foundation.

(5)Static compacted concrete precast pipe pile: foundation pile construction has no vibration, no noise, and has little influence on the surrounding environment.

(6)Borehole pressure grouting superfluid concrete pile: the abandoned soil and mud produced by foundation pile construction have a certain influence on the surrounding environment.

Table 1. main calculation results of the northwest high-rise building

\begin{tabular}{|c|c|c|c|c|c|}
\hline \multirow{2}{*}{ The pile type } & \multirow{2}{*}{$\begin{array}{l}\text { The pile } \\
\text { diameter } \\
(\mathrm{mm})\end{array}$} & \multirow{2}{*}{$\begin{array}{l}\text { construction } \\
\text { technology }\end{array}$} & \multirow{2}{*}{$\begin{array}{l}\text { Characteristic value of } \\
\text { bearing capacity of } \\
\text { single pile }(\mathrm{kN})\end{array}$} & $\begin{array}{l}\text { The pile top } \\
\text { elevation }(\mathrm{m})\end{array}$ & \multirow{2}{*}{$\begin{array}{l}\text { pile length } \\
\quad(\mathrm{m})\end{array}$} \\
\hline & & & & (m) & \\
\hline cast-in place pile & 600 & & 300 & -5 & 15 \\
\hline $\begin{array}{l}\text { cast-in place pile - } \\
\text { After grouting }\end{array}$ & 600 & After grouting & 386 & -5 & 15 \\
\hline cast-in place pile & 700 & & 350 & -5 & 15 \\
\hline $\begin{array}{l}\text { cast-in place pile - } \\
\text { After grouting }\end{array}$ & 600 & After grouting & 451 & -5 & 15 \\
\hline cast-in place pile & 800 & & 401 & -5 & 15 \\
\hline $\begin{array}{l}\text { cast-in place pile - } \\
\text { After grouting }\end{array}$ & 600 & After grouting & 515 & -5 & 15 \\
\hline precast pile & 600 & & 322 & -5 & 15 \\
\hline precast pile & 800 & & 430 & -5 & 15 \\
\hline
\end{tabular}

Based on comprehensive consideration of geological conditions, internal forces at the bottom of walls and columns and requirements for retaining soil of the structure, cap + pile foundation is selected as the main 
monomer of the structure. After comprehensive analysis of the aforementioned technology and economy, the pile type is bored and pressurized superfluid concrete pile with $600 \mathrm{~mm}$ diameter and $29 \mathrm{~m}$ effective pile length. The pile tip bearing layer is (6) coarse sand layer.According to the calculation of geological conditions, the characteristic value of vertical bearing capacity of single pile is $1500 \mathrm{kN}$, and the characteristic value of horizontal bearing capacity of single pile is $150 \mathrm{kN}$.For the wall bearing the lateral pressure of soil pile, part of the lateral pressure should be transmitted to the other pile foundations through the waterproof plate, and part should be borne by the pile foundation under the wall.

\subsection{Drawing pile design}

The groundwater type of the proposed site is mainly pore diving, and the stable water level elevation is $112.82 \mathrm{~m}$ $116.42 \mathrm{~m}$. The water level varies with the season and the annual variation range is $1.0-2.0 \mathrm{~m}$. The anti-floating fortification water level of the proposed basement shall be fortified at $1.80 \mathrm{~m}(118.00 \mathrm{~m})$ below the leveling elevation of the site.The pull-out pile is mainly used for the pile with a diameter of 600 in the basement of -5 meters. After the pile is 20 meters long, the pile is grouted, with an average of one pile every 5 meters.

\subsection{Pile test and inspection}

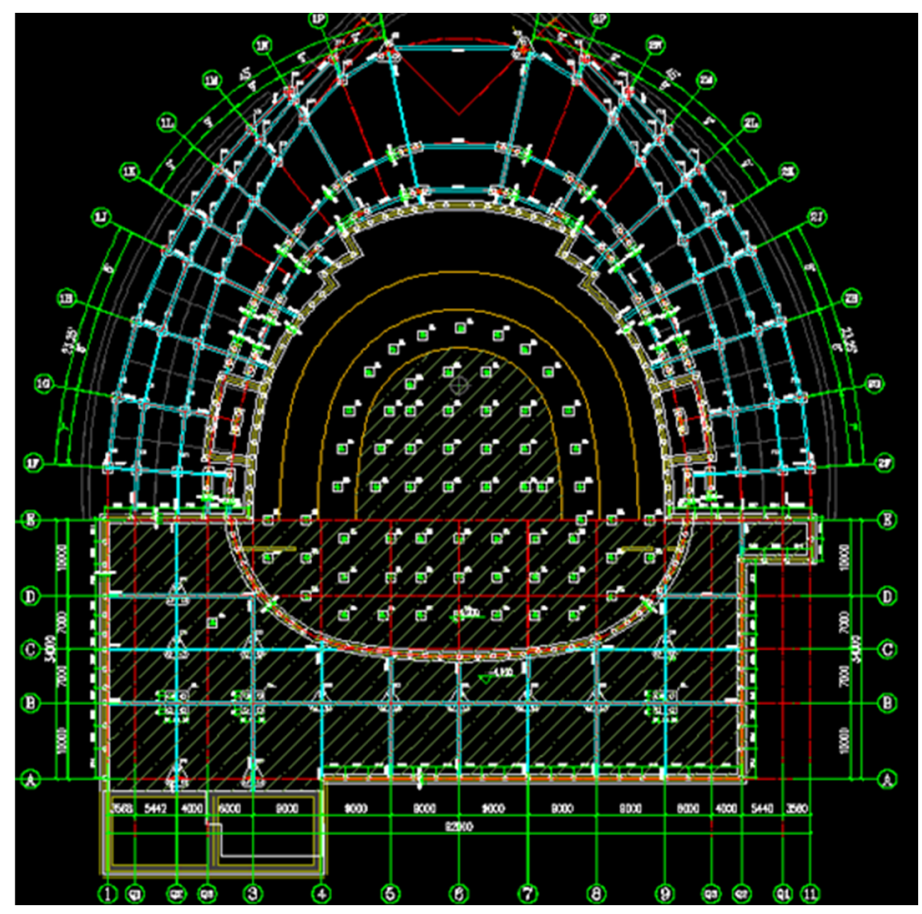

Figure 2. Pile foundation design drawing.

\section{Conclusion}

This paper introduces the foundation selection and structural design of Harbin Ice and Snow World project, verifies the feasibility of the project implementation, and
In order to ensure the safety and reliability of the implementation of this scheme, representative locations should be selected for pile foundation testing and testing in strict accordance with relevant specifications such as Technical Code for Building Pile Foundations JGJ 942008 and Technical Code for Building Pile Testing JGJ 106-2014.

(1) Before foundation pile construction, pile test should be carried out in different sections of the site. At the same time, personnel from relevant units such as survey, design and supervision should be timely informed to participate in the test. Pile forming control standards should be determined according to the results of site test.

(2) During the construction of static compacted concrete precast pile, the elevation of pile top and horizontal displacement of soil should be detected. If abnormal conditions are found, preventive measures such as redrilling and drilling holes should be taken in time.

(3) Vertical bearing capacity of single pile should be determined by field static load test.

(4) After foundation pile construction, bearing capacity and pile quality inspection should be carried out according to relevant specifications.

\subsection{Pile foundation layout}

Through comparison of different pile foundations, Design according to specifications ${ }^{[5]}{ }^{[6]}$, the schematic diagram of pile foundation design is shown in Figure 2.

analyzes the rationality of structural foundation layout through structural design and structural calculation analysis. 


\section{References}

1. Code for seismic design of buildings GB 500112010 [s] Beijing China building industry press

2. Geotechnical Engineering Investigation Report of Harbin Ice and Snow World Project [J]China Railway Modern Survey and Design Institute Co. Ltd

3. Technical Code for Building Plie Foundations JGJ942008[s]Beijing China building industry press.

4. Code for design of builiding foundation GB 50007-2011[s] Beijing China building industry press.

5. Load code for the design of building structures GB 50092012[s] Beijing China building industry press .

6. Code for design of concrete structures GB500102010: GB 50010 - 2011 [S] Beijing China building industry press, 2011. 